\title{
Relation between bruxism and dental implants
}

\author{
Relação entre bruxismo e próteses sobre implantes
}

Leonardo Bueno TORCATO'

Paulo Renato Junqueira ZUIM ${ }^{1}$

Daniela Atili BRANDINI²

Rosse Mary FALCÓN-ANTENUCCI ${ }^{1}$

\section{ABSTRACT}

Objective

The aim of this study was to gather information and discuss the predictability of implant-supported prostheses in patients with bruxism by performing a literature review.

\section{Methods}

In order to select the studies included in this review, a detailed search was performed in PubMed and Medline databases, using the following key words: bruxism, dental implants, implant supported prosthesis, and dental restoration failure. Items that were included are: case reports, randomized controlled trials, in vitro studies, literature and systematic reviews, with or without meta-analysis, of the last 20 years that addressed the theme. Articles without abstracts, animal studies, articles in languages other than English and articles from journals unrelated to the dental field were excluded.

\section{Results}

after analysis according to inclusion and exclusion criteria, 28 articles were selected from a total of 54. It is known from the array of scientific articles which have assessed, either through retrospective, prospective or experimental studies, that the biomechanical and biological impact of bruxism on implant-supported prostheses is small, and that the literature has contributed little to exemplify the prosthetic limits of safety for the specialist from a clinical point of view.

\section{Conclusion}

Although there is still no general consensus on this matter, most of the literature review articles do provide clinical guidelines that contribute to implant supported prostheses longevity and stability in patients with bruxism.

Indexing terms: Bruxism. Dental implantation. Dental prosthesis.

\section{RESUMO}

\section{Objetivo}

Realizar uma revisão sistemática, a fim de reunir informações e discutir a previsibilidade de próteses sobre implantes em pacientes com bruxismo.

\section{Métodos}

Para a identificação dos estudos dessa revisão, foi realizada uma estratégia de busca detalhada e avançada nos bancos de dados PubMed e Medline. Foram utilizados como descritores: bruxismo, implantes dentários, prótese implantossuportada e falha da restauração dentárial; bruxism, dental implants, implant-supported prosthesis e dental restoration failure. Os critérios de inclusão foram: artigos clínicos, estudos controlados aleatórios, estudos in vitro, revisões de literatura e revisões sistemáticas com e sem meta-análise dos últimos 20 anos que abordassem o tema proposto. Os critérios de exclusão foram: artigos sem resumo, estudos em animais, artigos cujo idioma não fosse o inglês e artigos de periódicos que não pertencessem à área odontológica.

\section{Resultados}

De um total de 54 artigos, após uma análise segundo o critério de inclusão e exclusão, foram selecionados 28 artigos. É sabido que a quantidade de artigos científicos que avaliaram, seja através de estudos retrospectivos, prospectivos ou experimentais, o impacto biológico e biomecânico do bruxismo em próteses sobre implantes é pequena e pouco tem contribuído para melhor exemplificação e discernimento dos limites protéticos de segurança para o especialista sob um ponto de vista clínico.

\section{Conclusão}

Portanto, ainda não há um consenso geral acerca desse assunto, porém, a maioria dos artigos de revisão de literatura fornecem guias de orientação clínica, os quais auxiliam na longevidade e estabilidade de próteses sobre implantes em pacientes com bruxismo.

Termos de indexação: Bruxismo. Implantação dentária. Prótese dentária.

\footnotetext{
${ }^{1}$ Universidade Estadual Paulista Júlio de Mesquita Filho, Faculdade de Odontologia, Departamento de Materiais Odontológicos e Prótese. Rua José Bonifácio, 1193, Vila Mendonça, 16015-050, Araçatuba, SP, Brasil. Correspondência para / Correspondence to: LB TORCATO. E-mail: <leonardotorcato@yahoo.com.br>

${ }^{2}$ Universidade Estadual Paulista Júlio de Mesquita Filho, Faculdade de Odontologia, Departamento de Cirurgia e Clínica Integrada. Araçatuba, SP, Brasil.
} 


\section{INTRODUCTION}

From the beginning of Implantodontics, implant supported prostheses have been a predictable treatment option for patients with partial or complete loss of teeth ${ }^{1-2}$. This is confirmed by long term longitudinal studies, which have shown that more than $95 \%$ of dental implants can remain intact over a period of 8 to 10 years ${ }^{3-4}$.

Notwithstanding, several complications may affect the success of bone integrated implants in specific situations ${ }^{5}$, which can be of a biological of biomechanical nature. According to El Askary et al. ${ }^{6}$, the signs of implant failure are: loosening or breaking of the screws that hold the crowns and abutments in place, edema or bleeding of soft tissue surrounding the implant, purulent exudate from the peri-implant sulcus, pain (rare), prosthesis fracture, angular bone loss and chronic infections.

Biomechanically, parafunctional loads on natural teeth or implants are characterised by constant and repetitive occlusal contacts. They are considered harmful to the stomatognathic system ${ }^{7}$, and their effects depend on the magnitude and direction of the forces ${ }^{8}$. Naert et al. ${ }^{9}$ have indicated that overload caused by parafunctional habits is the most likely cause of dental implant and marginal bone tissue loss. The types of occlusal parafunction that were included are bruxism, thumb sucking, lingual interposition and abnormal maxillomandibular relation ${ }^{10}$.

Bruxism is a parafunction that can be defined as a disorder in the typical movement of the masticatory system, and is characterised by grinding and clenching of the teeth during sleep or awake ${ }^{11-12}$. It can increase the magnitude and frequency of the forces applied to the bone tissue that supports the implant and result in destructive lateral loads, thus contributing to potential flexion caused by overload ${ }^{13}$.

The prevalence of bruxism in adult populations is approximately $10 \%$, and opinions on this parafunction are still divided with regard to the clinical restrictions this condition may imply for oral rehabilitation using dental implants ${ }^{14-15}$. The aim of this study was to gather information and discuss the predictability of implant supported prostheses in patients with bruxism by reviewing relevant literature.

\section{METHODS}

In order to select the studies included in this review, a detailed search was performed in PubMed and Medline databases, using the following key words to perform a Boolean search: bruxism, dental implants, implant supported prosthesis, and dental restoration failure. Items that were included are: case reports, randomized controlled trials, in vitro studies, literature and systematic reviews, with or without meta-analysis, of the last 20 years that addressed the theme. Articles without abstracts, animal studies, articles in languages other than English and articles from journals unrelated to the dental field were excluded. After analysis according to inclusion and exclusion criteria, 28 articles were selected from a total of 54. The obtained data were then analysed, crossreferenced and debated in order to reach conclusions.

\section{RESULTS}

Wannfors et al. ${ }^{16}$ compared the success of dental implants after one year with the surgical differences between raising of the jaw cavity and bone graft of 1 and 2 surgical stages. Forty patients with edentulous maxillae were selected for clinical assessment. In this study, the risk of implant failure in non-grafted areas was found to be significantly lower than in grafted areas, regardless of the technique used. The individual risk of implant failure was, however, about twice as high in areas grafted using the single stage surgical procedure than in in areas where the two stage procedure was used. With regard to the factors that potentially influence the stability of implants, a positive correlation was found between bruxism and implant failure, independent of the surgical technique used.

Ekfeld et al. ${ }^{17}$ verified the factors that influence implant failure. Through this retrospective study, 54 patients with edentulous jaws were attended between January 1988 and December 1996. In order to reduce systematic errors, the population was equally divided into an experimental and a control group according to personal data (age, gender). Among the circumstances present in the population were bruxism, personal sadness, depression, as well as cigarette, alcohol or drug addiction.

From a total of 301 implants, 150 were installed in control group patients and 151 in the experimental group. In the latter, 128 implants were lost; 55 before load were applied, 46 in the first year and 27 in the second year or later. Of the 73 delayed faults, the majority (63\%) occurred during the first year the implant was subjected to forces. In cases where implants were lost, the following conditions were observed: infections (6\%), insufficient initial stability $(12.6 \%)$, exposed thread at the moment of installation (4\%) and abnormal bleeding (4\%). This study suggests that there are certain important factors to be considered to prevent implant failure, such as insufficient supporting bone tissue, heavy smoking and bruxism. 
Chart 1. Articles included in the review.

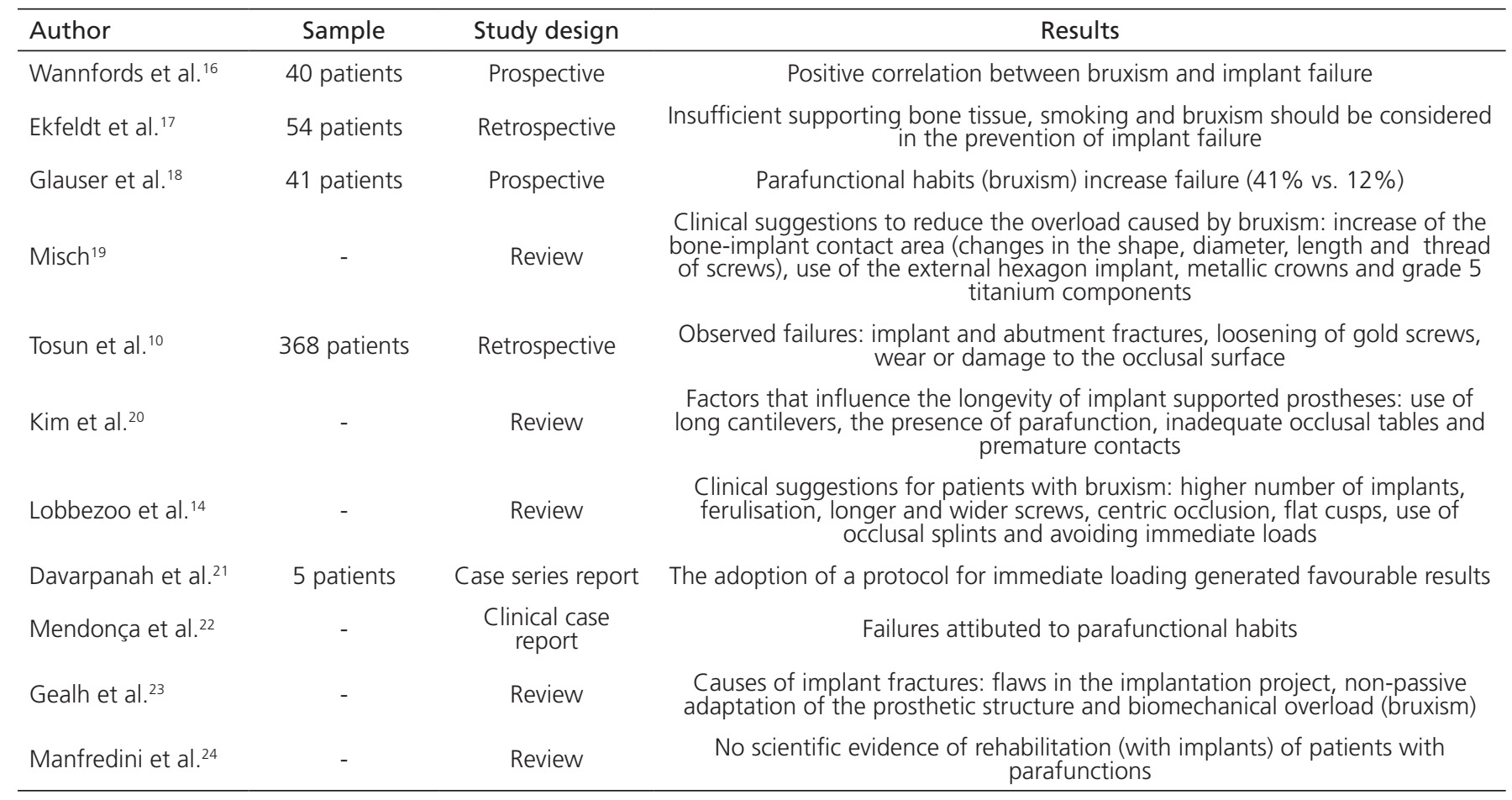

Glauser et al..$^{18}$ assessed short term success rates of immediate load implants in various parts of the jaw. In this study, 41 patients (19 men and 22 women, average age 52), received a total of 127 immediate load implants (76 in the maxillae and 51 in the mandibles). Clinical evaluation took place in week 1 and 2, and then 1, 2, 3, 6 and 12 months after the first load. Of the 127 implants, 105 were considered successful after 12 months, whereas 22 implants were lost in 13 patients. Thus, the cumulative success rate after 12 months was $82.7 \%$. On the other hand, implants in patients with parafunctional habits (bruxism) presented considerably more faults than implants in patients without parafunctions ( $41 \%$ compared to $12 \%$ ).

According to the literature review conducted by Misch ${ }^{19}$, forces can be defined in terms of magnitude, duration, direction, type and frequency. When these variables increase, they can induce force patterns that are the primary cause of delayed dental implant failure.

With the objective of avoiding or minimising delayed implant failure, the author proposes a number of changes to the treatment plan: increasing the bone-implant contact area (changes in the shape, diameter, length and thread of screws); the use of grade 5 titanium components (which is four times stronger than conventional grade 1 CP titanium); instructing implantologists about the use of external hexagon implants (the larger internal diameter of the internal hexagon is about $40 \%$ less resistant); installing the external hexagon implants perpendicularly to the Wilson and Spee curves; using metallic occlusal surfaces; and mandibular excursions directed by the former guide.

Tosun et al. ${ }^{10}$ used polysomnographic analysis to confirm bruxism during sleep and assessed the results of clinical treatment for dental implants in patients with bruxism. A retrospective analysis was conducted with 368 patients, involving a total of 838 osseointegrated implants. Of the 19 patients that presented mechanical complications, 6 were diagnosed with nocturnal bruxism, detected by polysomnographic monitoring of the masseter muscle.

Most bruxism episodes (80\%) occurred in the stages of light sleep (stage 1 and 2), and all episodes of bruxism were followed by cardiac arrhythmia. The mechanical complications observed in this work were: implant and abutment fractures, loosening of gold screws, and wear or damage to the occlusal surface. Mechanical complications in patients without bruxism were related to non-passive adaptation to the prosthetic structure, premature occlusal contacts and occlusal discrepancies, as well as faults in the impression material.

In their literature review, Kim et al. ${ }^{20}$ discussed the importance of occlusion for achieving long term success in dental implants. Considering that implants are more 
susceptible to occlusal overload, factors such as long cantilevers, parafunctions, inadequate occlusal surfaces and premature contacts can reduce the service life of implant supported prostheses. Therefore, the authors suggest aiming for perfect occlusion by increasing the bone-implant contact area, optimising the direction of forces (a 30-40\% decrease of the occlusal surface and inclination of the cusps, centric occlusal contacts, and flat central fossa) and reducing the magnitude of the force (ferulisation, homogeneous distribution of occlusal contacts, use of cantilevers wider than $15 \mathrm{~mm}$ ). Following these suggestions will cause loads to remain within the physiological limits, thus improving long term stability of prostheses and dental implants.

In accordance with the literature review conducted by Lobbezoo et al. ${ }^{8}$, bruxism is generally considered a contraindication for the installation of dental implants. Due to the fact that possible causal relations between bruxism and implant failure lack specific and consistent results, this study urges professionals to use a clinical guide when attending patients with bruxism. This guide concerns a higher number of implants, ferulisation where necessary, longer and wider implant screws, centric occlusion, flat cusps, use of occlusal splints and avoiding immediate loads.

Davarpanah et al. ${ }^{21}$ evaluated the success rate of an immediate load protocol in multiple-risk partially edentulous patients with faulty prostheses and teeth to be extracted. A total of 44 immediate load implants were installed in the maxillae of 5 patients, 3 of which with parafunctional habits (bruxism). Although the total implant failure rate was $13.4 \%$ (20\% in scarred areas and $8.82 \%$ in sockets of recently extracted teeth), the prosthesis success rate was $100 \%$, which led the authors to conclude that the immediate load protocol produced favourable results.

Mendonça et al. ${ }^{22}$ elaborated on a clinical case regarding a patient with bruxism who received a mandibular implant-supported overdenture implant. Two years after installation of the prosthesis, an implant fracture occurred. One of the options to resolve the implant failure was to modify the implant by installing a new abutment and replace only part of the bridge, allowing for the same prosthesis to be used again. Not only did this save time, it also provided the patient with a higher degree of comfort. The authors attributed the implant failure to the parafunctional habits described by the patient in the clinical exam associated to the history of loosening screws and abutments.

Gealh et al. ${ }^{23}$ researched the literature in order to identify the causal factors that can lead to dental implant failure, and to discuss available procedures to prevent the occurrence of failures. According to the authors, the causes of implant fractures can be grouped into 3 categories: defects in the implantation project, non-passive adaptation of the prosthetic structure and biomechanical overload (bruxism). Although the chance of implant fracture is low, its occurrence is highly frustrating for patients. The most common solution to this problem is the surgical removal of the broken fragment, the installation of a new implant, and confection of a substitute prosthesis.

Manfredini et al. ${ }^{24}$ discussed current concepts about the aetiology, diagnosis and treatment of bruxism, as well as its impact on dental implants. Their aim was to formulate adequate clinical suggestions, based on scientific evidence gathered in a literature review. However, the authors noted that little is known about the biological and biomechanical effects of dental implantation treatment in patients with bruxism. In addition, they suggested that the lack of available data is the result of specialists' opinions, rather than based on scientific evidence.

\section{DISCUSSION}

A negative causal relation appears to exist between oral rehabilitation using dental implants and a parafunction in the stomatognathic system (bruxism in this case). According to Wannfors et al. ${ }^{16}$ and Ekfeldt et al. ${ }^{17}$, a significantly higher number of implant failures was observed among patients with bruxism than in patients without masticatory muscle hyperactivity. Furthermore, it can be noted that the type of implant failure was quite similar in both studies, with approximately $50 \%$ of failures occurring in the first surgical stage, and $50 \%$ in the second.

The above results are confirmed by Esposito et al. ${ }^{25}$, who concluded after a meta-analysis of several studies that $50 \%$ of implant failures occur immediately after installation of the prosthesis and another $50 \%$ when the implant is subjected to functional loads. It is likely that most immediate failures result from factors related to the patient and the employed surgical procedure, whereas delayed failures can be attributed to occlusal overload during functional use. In this way, it has been demonstrated under experimental conditions that dental implants can break as a result of excessive occlusal load ${ }^{26}$.

In contrast, Davarpanah et al. ${ }^{21}$ observed a $13.4 \%$ failure rate immediately following installation, considerably higher than the failure rates under delayed or 
early load protocols (up to two weeks after installation of the implant), which are approximately $2-4 \%{ }^{27-28}$. Despite the high failure rate and the clinical characteristics of the patients that participated in the study, among which figured poor oral hygiene, susceptibility to periodontal disease, parafunctional habits (bruxism) and tobacco use, results in a 24 month time scale proved favourable with regard to implant stability and prosthesis success. However, the weakness of this study is its small sample size $(n=5)$, which, particularly in a time series study design where all risk factors are grouped together, may result in unreliable results.

Glauser et al. ${ }^{18}$ identified a higher failure rate in the group with bruxism than among non-bruxers $(41 \%$ compared to $12 \%)$. It should be noted, however, that only 22 implants (17.3\%) were lost and a cumulative success rate of $82.7 \%$ was achieved. These figures do not fully correspond with the assessed literature, which is likely due to the small sample size and the fact that no parameter that could result in implant failure was as such identified with statistical significance $(\alpha=0.05)$. On the other hand, bruxism and posterior maxillary bone quality demonstrated only a tendency towards statistical significance.

There is still a lack of consensus about the effect of parafunctional loads originating from bruxism on implant supported prostheses. Longitudinal clinical studies are scarce and, together with clinical case studies, merely suggest a positive correlation between dental implant failure and bruxism. Due to the fact that other risk factors, such as insufficient hygiene, presence of periodontal diseases and tobacco use, are assessed in combination with parafunctional habits, prosthetic planning and surgical approach vary per case. Finally, the difficulty to diagnose bruxism (few studies adopt polysomnography in association with the clinical exam) is responsible for the low degree of reliability and generalisability of the available data.

Despite divergence in the considerations in the evaluated studies, most literature reviews ${ }^{8,19-20}$ stress the importance of providing clinical guides to better manage and control patients with bruxism during oral rehabilitation

\section{REFERENCES}

1. Brånemark PI, Adell R, Breine U, Hansson BO, Lindström J, Ohlsson A. Intra-osseous anchorage of dentalprostheses. I. Experimental studies. Scand J Plast Reconstr Surg. 1969;3(2):81100. doi: 10.3109/02844316909036699. treatment with implant supported prostheses. These guides should address measures, aimed at increasing the longevity and stability of implants and prostheses, which can be taken during the pre-surgical planning and execution of the treatment.

The main suggestions presented by the authors included in this review can be summarised as follows: increase the bone-implant contact area (number of implants, diameter, length, surface treatment and tread shape of screws); elimination of cantilevers where possible; installation of external hexagon implants (thicker internal walls), disocclusion by anterior guide (eliminates or reduces posterior lateral loads); metallic crowns (less prone to fracture than porcelain); and use of occlusal splints.

\section{CONCLUSION}

Few articles have evaluated, trough retrospective, prospective or experimental studies, the biological and biomechanical impact of bruxism on implant supported prostheses. As a consequence, there isn't much material to provide specialists with examples and safety margins from a clinical perpective when performing dental implantation treatment. It can also be noted that the body of knowledge on the subject does not present a broad consensus based on scientific evidence. Notwithstanding, the literature has produced clinical guides with relevant theoretical suggestons to aid prosthetic specialists in the treatment of patients with bruxism. If bruxism were to be considered a criteria of inclusion rather than exclusion, the relation between bruxism and implant supported prostheses may become the object of studies that enable the clarification of this relation and subsequent establishment of general consensus in the near future.

\section{Collaborators}

LB TORCATO and RM FALCÓN-ANTENUCCI were responsible for researching the databases, selecting articles and text writing. PRJ ZUIM and DA BRANDINI assisted in the selection of the theme and revised the article.

2. Adell $\mathrm{R}$, Eriksson $\mathrm{B}$, Lekholm $\mathrm{U}$, Brånemark $\mathrm{PI}$, Jemt $\mathrm{T}$. A longterm follow-up study of osseointegrated implants in the treatment of totally edentulous jaws. Int J Oral Maxillo-fac Implants. 1990;5(4):347-59.

3. Sethi A, Kaus T. Maxillary ridge expansion with simultaneous implant placement: 5-year results of an ongoing clinical study. Int J Oral Maxillofac Implants. 2000;15(4):491-9. 
4. Ferrigno N, Laureti M, Fanali S, Grippaudo G. A long-term follow-up study of non-submerged ITI implants in the treatment of totally edentulous jaws. Part I: ten-year life table analysis of a prospective multicenter study with 1286 implants. Clin Oral Implants Res. 2002;13(3):260-73. doi: 10.1034/j.16000501.2002.130305.x

5. Naert I, van Steenberg D, Worthington P. Osseointegration in oral rehabilitation: an introduction. Quintessence: Chicago; 1993.

6. el Askary AS, Meffert RM, Griffin T. Why do dental implants fail? Part I. Implant Dent. 1999;8(2):173-85.

7. Ramfjord SP, Ash MM. Occlusion. $2^{\text {nd }}$ ed. Philadelphia: WB Saunders; 1971.

8. Lobbezoo F, Brouwers JE, Cune MS, Naeije M. Dental implants in patients with bruxing habits. J Oral Rehabil. 2006;33(2):152-9. doi: 10.1111/j.1365-2842.2006.01542.x.

9. Naert I, Quirynen M, van Steenberghe D, Darius P. A study of 589 consecutive implants supporting complete fixed prostheses. Part II: prosthetic aspects. J Prosthet Dent. 1992;68(6):949-56. doi:10.1016/0022-3913(92)90557-Q

10. Tosun T, Karabuda C, Cuhadaroglu C. Evaluation of sleep bruxism by polysomnographic analysis in patients with dental implants. Int J Oral Maxillofac Implants. 2003;18(2):286-92.

11. Thorpy MJ. Parasomnias. In: Thorpy MJ. International classification of sleep disorders: diagnostic and coding manual. Allen Press: Rochester; 1990.

12. Okeson JP. Orofacial pain: guidelines for assessment, diagnosis and management. Chicago: Quintessence; 1996.

13. Rangert $B$, Krogh PHJ, Langer B, van Roekel N. Bending overload and implant fracture: a retrospective clinical analysis. Int J Oral Maxillofac Implants. 1995;10(3):326-34.

14. Lobbezoo F, van der Zaag J, Visscher CM, Naeije M. Oral kinesiology. A new postgraduate programme in The Netherlands. J Oral Rehabil. 2004;31(3):192-8. doi: 10.1046/j.0305182X.2003.01244.x

15. Misch CE. Occlusal considerations for implant-supported prostheses. In: Misch CE. Contemporary implant dentistry. St Louis: Mosby; 1993. p. 705-33.

16. Wannfors K, Johansson B, Hallman M, Strandkvist T. A prospective randomized study of 1 - and 2-stage sinus inlay bone grafts: 1-year follow-up. Int J Oral Maxillofac Implants. 2000;15(5):625-32.

17. Ekfeldt $A$, Christiansson $U$, Eriksson $T$, Lindén $U$, Lundqvist $S$, Rundcrantz $T$ et al. A retrospective analysis of factors associated with multiple implant failures in maxillae. Clin Oral Implants Res. 2001;12(5):462-7. doi: 10.1034/j.1600-0501.2001.120505.x
18. Glauser R, Rée A, Lundgren A, Gottlow J, Hämmerle CH, Schärer P. Immediate occlusal loading of Brånemark implants applied in various jawbone regions: a prospective, 1 -year clinical study. Clin Implant Dent Relat Res. 2001;3(4):204-13. doi: 10.1111/j.17088208.2001.tb00142.x

19. Misch CE. The effect of bruxism on treatment planning for dental implants. Dent Today. 2002;21:76-81.

20. Kim Y, Oh TJ, Misch CE, Wang HL. Occlusal considerations in implant therapy: clinical guidelines with biomechanical rationale. Clin Oral Implants Res. 2005;16(1):26-35. doi: 10.1111/j.16000501.2004.01067.x

21. Davarpanah $M$, Caraman M, Jakubowicz-Kohen B, Kebir-Quelin $M$, Szmukler-Moncler S. Prosthetic success with a maxillary immediate-loading protocol in the multiple-risk patient. Int J Periodontics Restorative Dent. 2007;27:161-9. doi: 10.11607/ prd.00.0735

22. Mendonça G, Mendonça DB, Fernandes-Neto AJ, Neves FD. Management of fractured dental implants: a case report. Implant Dent. 2009;18(1):10-6. doi: 10.1097/ID.0b013e318192

23. Gealh WC, Mazzo V, Barbi F, Camarini ET. Osseointegrated implant fracture: causes and treatment. J Oral Implantol. 2011;37(4):499-503. doi: dx.doi.org/10.1563/AAIDJOI-D-09-00135.1

24. Manfredini D, Bucci MB, Sabattini VB, Lobbezoo F. Bruxism: overview of current knowledge and suggestions for dental implants planning. Cranio. 2011;29(4):304-12. doi: 10.1179/ crn.2011.045

25. Esposito M, Hirsch JM, Lekholm U, Thomsen P. Biological factors contributing to failures of osseointegrated oral implants. (I) Success criteria and epidemiology. Eur J Oral Sci. 1998;106(1):527-51. doi: 10.1046/j.0909-8836..t01-2-.x

26. Isidor F. Loss of integration caused by occlusal load of oral implants. A clinical and radiographic study in monkeys. Clin Oral Implants Res. 1996;7(2):143-52. doi: 10.1034/j.16000501.1996.070208.x

27. Albrektsson T, Sennerby L. State of the art in oral implants. J Clin Periodontol. 1991;18(6):474-81. doi: 10.1111/j.1600051X.1991.tb02319.x

28. Cochran DL, Buser $D$, ten Bruggenkate $C M$, Weingart $D$, Taylor TM, Bernard JP, et al. The use of reduced healing times on ITI implants with a sandblasted and etched (SLA) surface: early results from clinical trials on ITI SLA implants. Clin Oral Implants Res. 2002;13(2):144-53. doi: 10.1034/j.16000501.2002.130204.x

Received on: 18/3/2013

Final version resubmitted on: $26 / 12 / 2013$ Approved on: 28/3/2014 